\title{
Implementasi Metode Forward Chaining Pada Pengembangan Game Edukasi Warisan Budaya
}

\author{
Muhammad Bambang Firdaus ${ }^{1 *}$, Ummul Hairah ${ }^{2}$, Arief Hidayat ${ }^{3}$, \\ Andi Tejawati ${ }^{4}$, M Khairul Anam ${ }^{5}$, Nariza Wanti Wulan Sari ${ }^{6}$ \\ 1,2,3,4 Informatika, Universitas Mulawarman, Samarinda \\ ${ }^{5}$ Teknologi Informarsi, STMIK AMIK Riau, Pekanbaru \\ ${ }^{6}$ Universitas Mulia, Balikpapan \\ *bambangf@fkti.unmul.ac.id
}

\begin{abstract}
Indonesia is an archipelagic country with various types of cultural heritage, including traditional houses, traditional folk dances and musical instruments. However, today with the rapid advancement of technology, the existing cultural heritage is starting to be abandoned because of the large number of foreign cultures entering this country. The author carried out this research aimed at reintroducing cultural heritage to the community through media in the form of games that are adaptive to the players, one of which is by using the forward chaining method in its development. In practice, the forward chaining method is used to determine whether the player has the right to continue to the next level or not. Based on the results of the questionnaire obtained, it shows that $92.5 \%$ of respondents strongly agree that this game can help users get to know more about cultural heritage in Indonesia and $82.9 \%$ of respondents strongly agree that this game is interesting to play.
\end{abstract}

Keywords: forward chaining, game, Indonesian cultural heritage, media, adaptive

\begin{abstract}
Abstrak
Indonesia adalah negara kepulauan dengan beragam jenis warisan budaya, termasuk rumah tradisional, tarian daerah dan alat musik tradisional. Namun, dengan pesatnya kemajuan teknologi pada saat ini, warisan budaya yang ada mulai ditinggalkan karena banyaknya budaya dari luar yang masuk ke negeri kita. Penulis melaksanakan riset ini bertujuan untuk mengenalkan kembali warisan budaya kepada masyarakat melalui media berupa game yang adaptif terhadap pemainnya, salah satunya adalah dengan menggunakan metode forward chaining dalam pengembangannya. Dalam penerapannya, metode forward chaining digunakan untuk menentukan apakah pemain nantinya berhak lanjut ke level berikutnya atau tidak. Berdasarkan hasil kuisioner yang didapat menunjukkan bahwa 92,5\% responden mengemukakan pendapat sangat setuju jika dengan adanya game ini dapat membantu pengguna mengenal lebih banyak warisan budaya yang ada di Indonesia serta $82,9 \%$ responden sangat setuju bahwa game ini menarik untuk dimainkan.
\end{abstract}

Kata kunci: forward chaining, game, warisan budaya Indonesia, media, adaptif

\section{Pendahuluan}

Indonesia merupakan sebuah negara berkepulauan dengan jumlah pulau sebanyak kurang lebih 16,648 yang dilaporkan ke Perserikatan Bangsa-Banga, serta populasi penduduk kurang lebih 269,435,770 juta jiwa pada bulan desember tahun 2019, data ini mengacu pada data pokok Kemendagri. Dengan jumlah pulau dan penduduk sebanyak itu, Indonesia punya berbagai macam kebudayaan dari tarian, senjata tradisional, lagu daerah, alat musik tradisional, lagu daerah, rumah adat dan masih banyak lagi. Hingga tahun 2020, ada lebih dari 4,432 warisan budaya Indonesia yang telah diakui oleh Kemendikbud, antara lain warisan budaya tak benda dan warisan budaya benda, data ini mengacu pada statistik kebudayaan 2020.

Kebanyakan orang sangat menyukai permainan. Berdasarkan data Appbrain, terdapat bukti sebanyak 59.059 puzzle di Google Play, 55.900 casual games, 60.897 arcade, 30.384 action games dan 28.204 
education games. Hal ini menunjukkan bahwa masih kurangnya edukasi dalam kaitannya dengan game genre lainnya [1].

Dalam rangka usaha menyajikan pendidikan yang bervariatif, game edukasi yang dibuat perlu lebih menarik dan tidak membosankan. Maka dirasa perlu sebuah sistem yang bisa menjadi opsi, bersifat adaptif terhadap pengguna sehingga mampu memenuhi kemampuan pengguna. Salah satunya ialah tingkat kesulitan game untuk melanjutkan level selanjutnya (levelling) [2].

Terdapat beberapa penelitian terdahulu mengenai levelling dan pengacakan soal seperti yang dilakukan oleh Alpin \& Suzuki Syofian tahun 2020, Hasil penelitian menjelaskan mengapa setiap pertanyaan dalam game menarik dan mengetahui cara menjaga kebersihan lingkungan agar kota tetap bersih melalui media game interaktif Android.

Kemudian penelitian yang dilakukan oleh Teguh Arifianto, M. Nurfaizin \& Moh. Aries Syufagi pada tahun 2017, Hasil penelitian menjelaskan bahwa konsep algoritma balap karung digunakan untuk mengevaluasi proses dan untuk memindahkan pengambil keputusan ke tahap selanjutnya. 4 (empat) aturan yaitu life, objective, score dan strength, merupakan aturan yang digunakan dalam metode forward chaining ini.

Penelitian ini mememiliki beberapa tujuan yang ingin dicapai yaitu menerapkan metode forward chaining pada game edukasi warisan budaya Indonesia serta mengembangkan game edukasi yang dapat memperkenalkan warisan budaya Indonesia.

\section{Metoda Penelitian}

Penelitian ini mengembangkan game edukasi yang dibangun menggunakan model prototype. Protoype merupakan sebuah paradigma pengembangan baru untuk perangkat lunak, yang tidak hanya memberikan pilihan baru pada dunia pengembangan perangkat lunak [3], tetapi juga merevolusi metode pengembangan perangkat lunak lama [4], sistem sekuensial yang umumnya dikenal sebagai siklus hidup pengembangan sistem[5] [6].

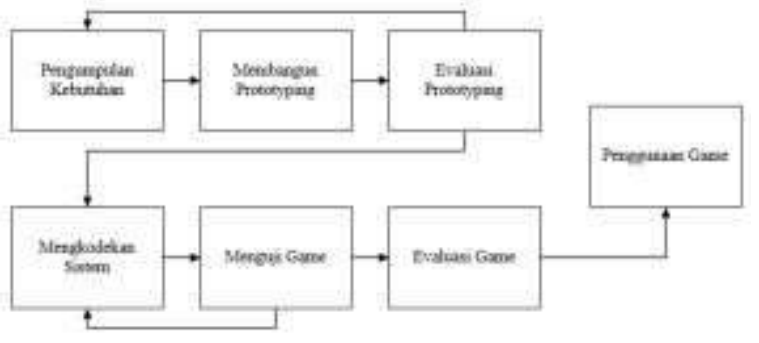

Gambar 1. Tahapan - Tahapan Model Prototype

Tahapan penelitian ini akan mengacu sesuai dengan Gambar 1, dimulai dari pengumpulan kebutuhan hingga evaluasi dan penggunaan game. Detail penjelasan tahapantahapan model prototype dalam pengembangan game ini dijelaskan dengan rincinan, antara lain:

\subsection{Pengumpulan Kebutuhan}

Dalam tahap pengumpulan kebutuhan, berbagai aspek yang dibutuhkan dalam pembuatan game ini harus disiapkan sebaik mungkin [7], dari pengumpulan objek game yang didapatkan dari studi literatur untuk digunakan sebagai bahan kuis, menentukan tahap levelling, scoring, dan poin, serta pemilihan software dan hardware yang cocok untuk digunakan dalam membuat game tersebut [8][9].

\subsection{Membangun Prototyping}

Pada tahap ini yang dilakukan adalah membuat gambaran game berupa sebuah mock up dengan tujuan agar game yang dihasilkan sesuai dengan kebutuhan, peneliti membuat desain gambaran visual dari tampilan game sebagai preview seperti apa wajah dari hasil aplikasi nantinya [10], hasil mock up ini dijadikan acuan dalam merancang tampilan game [11]

Mock up yang menjadi prioritas pada aplikasi ini adalah visualisasi menu utama dan visualisasi saat bermain, karena kedua hal ini merupakan fungsi utama game[12]. Hasil mock up untuk dua tampilan yang dimaksud dapat dilihat pada gambar 2 dan gambar 3 . 


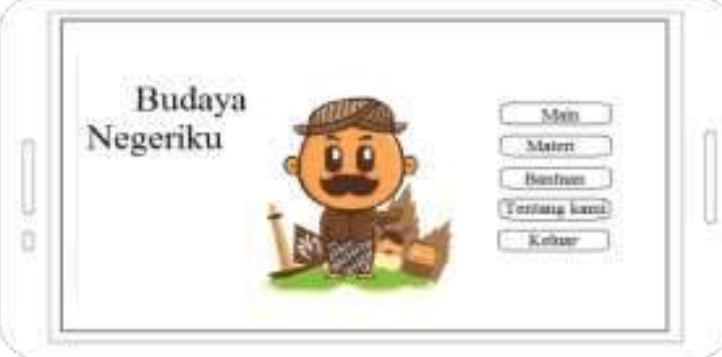

Gambar 2. Mock up Menu Utama

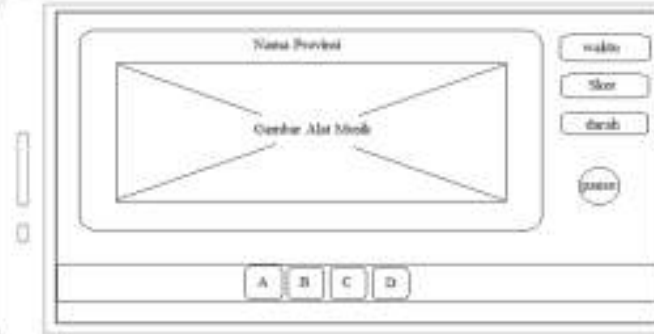

Gambar 3. Mock up saat bermain

Tahapan selanjutnya setelah merancang mock up adalah perancangan alur game, mulai dari game dijalankan hingga berakhir [13]. Alur tersebut digambarkan dalam dua bentuk diagram yaitu flowchart, dan activity diagram [14], bentuk lengkap dari diagram yang dimaksud dapat dilihat pada Gambar 4 dan Gambar 5.

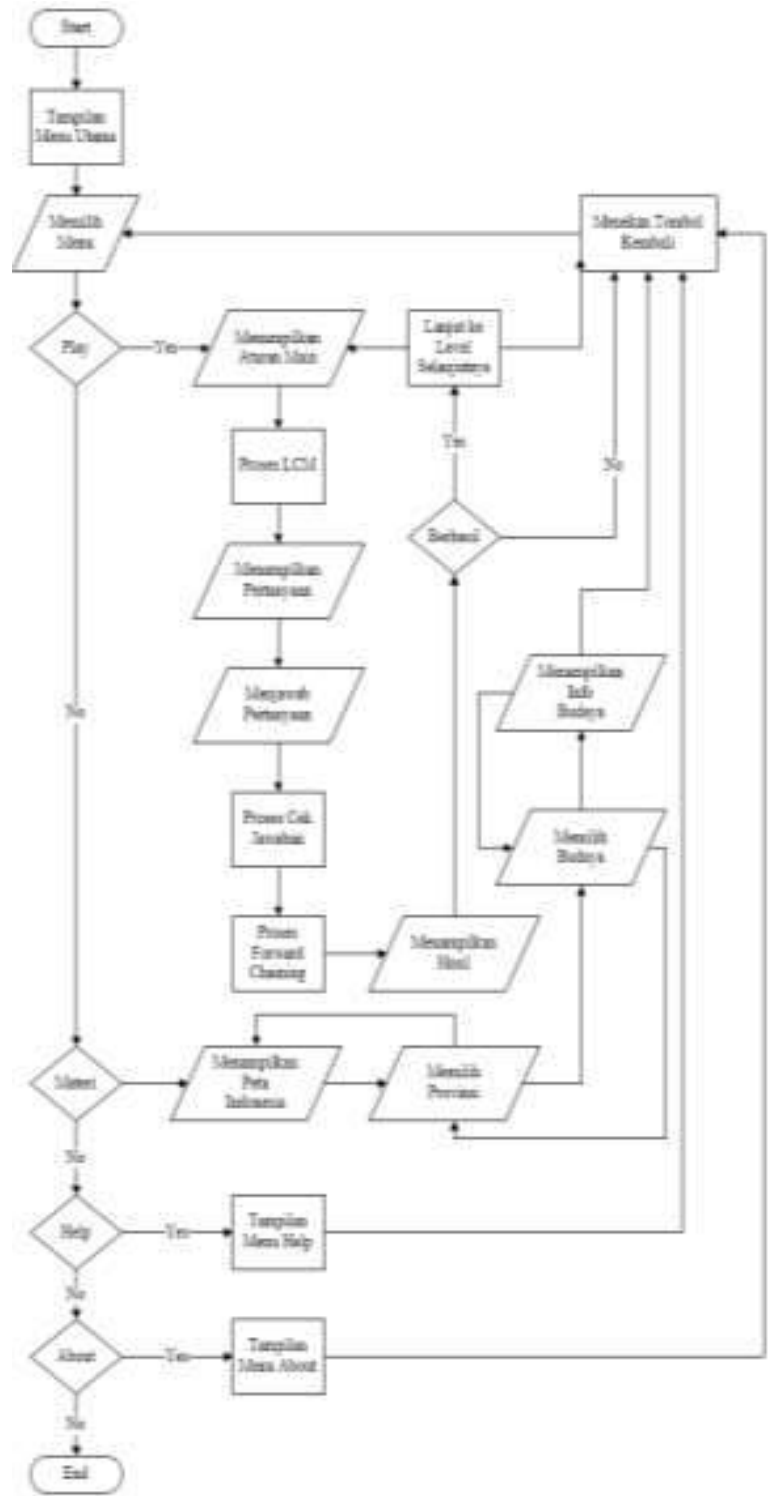

Gambar 4. Flowchart Game 


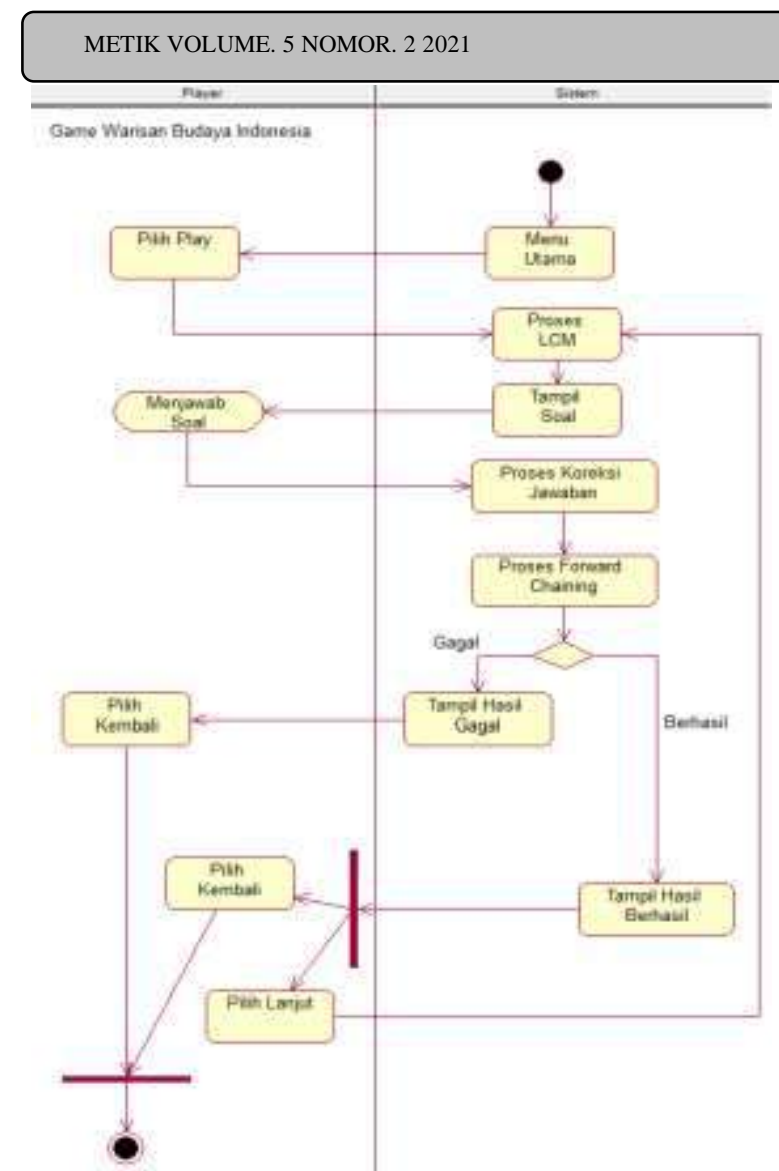

Gambar 5. Activity Diagram Play

Membuat rancangan forward chaining yang digunakan untuk levelling (lanjut tidaknya pemain ke level berikutnya), dengan menentukan variabel rule dan variabel hasil.

Tabel 1. Variabel Rule

\begin{tabular}{|c|c|c|c|}
\hline No. & $\begin{array}{l}\text { Kode } \\
\text { Rule }\end{array}$ & Kondisi & Keterangan \\
\hline 1 & R1 & $\begin{array}{c}{[1,2,3,4,5,6,7,8} \\
9,10]\end{array}$ & $\begin{array}{c}\text { Jawaban } \\
\text { Benar }\end{array}$ \\
\hline 2 & $\mathrm{R} 2$ & {$[1,2,3]$} & Nyawa \\
\hline \multicolumn{4}{|c|}{ Tabel 2. Variabel Hasil } \\
\hline No. & $\begin{array}{l}\text { Kode } \\
\text { Rule }\end{array}$ & \multicolumn{2}{|c|}{ Keterangan } \\
\hline 1 & $\mathrm{H} 01$ & \multicolumn{2}{|c|}{$\begin{array}{c}\text { Perfect, Jawaban Benar, Bintang } \\
\text { 3, Lanjut Level }\end{array}$} \\
\hline 2 & H02 & \multicolumn{2}{|c|}{$\begin{array}{c}\text { Jawaban Benar, Bintang 2, } \\
\text { Lanjut Level }\end{array}$} \\
\hline 3 & $\mathrm{H} 03$ & \multicolumn{2}{|c|}{$\begin{array}{c}\text { Jawaban Benar, Bintang 1, } \\
\text { Lanjut Level }\end{array}$} \\
\hline 4 & H04 & \multicolumn{2}{|c|}{ Game over, Ulang Game } \\
\hline
\end{tabular}

Kemudian pembuatan pohon inferensi (Inference Tree) dilakukan setelah penentuan variabel yang diperlukan untuk membantu pembentukan aturan yang kemudian diproses oleh mesin inferensi.

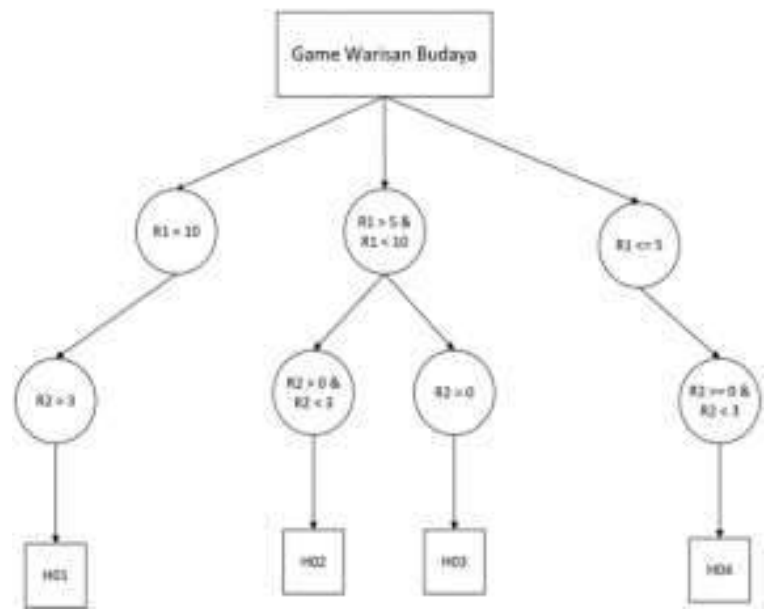

Gambar 6. Inference Tree hasil dan kondisi

Pada tahapan ini diubah menjadi algoritma pemrograman setelah fase pohon inferensi telah berlalu.

Tabel 3. Aturan Game Warisan Budaya Berdasarkan

\begin{tabular}{|c|c|c|}
\hline \multicolumn{3}{|c|}{ Hasil } \\
\hline No. & If & Then \\
\hline 1 & $\mathrm{R} 1=10$ dan $\mathrm{R} 2=3$ & H01 \\
\hline & $\begin{array}{l}\text { Jawaban benar }=10, \\
\text { sisa nyawa }=3\end{array}$ & $\begin{array}{c}\text { Perfect, Jawaban } \\
\text { benar, Bintang 3, } \\
\text { Lanjut Level }\end{array}$ \\
\hline 2 & $(\mathrm{R} 1>5$ dan $\mathrm{R} 1<10)$ & \\
\hline & $\begin{array}{l}\text { dan }(\mathrm{R} 2>0 \text { dan } \mathrm{R} 2< \\
\text { 3) }\end{array}$ & $\mathrm{H} 02$ \\
\hline & Jawaban benar $>5$ & Jawaban benar, \\
\hline & dan $<10$, serta sisa & Bintang 2, Lanjut \\
\hline & nyawa $>0$ dan $<3$ & Level \\
\hline 3 & $\begin{array}{l}(\mathrm{R} 1>5 \text { dan } \mathrm{R} 1<10) \\
\text { dan } \mathrm{R} 2=0\end{array}$ & $\mathrm{H} 03$ \\
\hline & $\begin{array}{l}\text { Jawaban benar }>5 \\
\text { dan }<10 \text {, sisa nyawa } \\
=0\end{array}$ & $\begin{array}{c}\text { Jawaban benar, } \\
\text { Bintang 1, Lanjut } \\
\text { Level }\end{array}$ \\
\hline 4 & $\begin{array}{l}\mathrm{R} 1<=5 \text { dan }(\mathrm{R} 2=>0 \\
\text { dan } \mathrm{R} 2<3)\end{array}$ & H04 \\
\hline & $\begin{array}{l}\text { Jawaban benar }<=5, \\
\text { sisa nyawa }>=0\end{array}$ & $\begin{array}{c}\text { Game Over, Ulang } \\
\text { Game }\end{array}$ \\
\hline
\end{tabular}

\subsection{Evaluasi Prototyping}

Kegiatan evaluasi dilakukan untuk mengetahui apakah mock up dan diagram yang telah dibuat sudah sesuai dengan kebutuhan yang dikumpulkan [15][16].

\subsection{Mengkodekan Sistem}

Setelah prototype yang dibuat sesuai, maka tahap berikutnya adalah membuat game berdasarkan prototype yang ada. Program yang digunakan untuk membuat game 
tersebut adalah Unity dengan menggunakan bahasa pemrograman java [17].

\subsection{Menguji Game}

Setelah game sudah selesai dibuat, maka perlu adanya pengujian terhadap game tersebut agar tidak ada bug ataupun error [18] [19].

\subsection{Evaluasi Game}

Setelah pengujian dilakukan, maka game diujikan kepada masyarakat umum dan agar masyarakat dapat memberikan tanggapan mereka terhadap program tersebut [20][21]. Setelah mengumpulkan tanggapan dari masyarakat maka dilakukanlah evaluasi terhadap game tersebut, seperti apakah sudah layak game tersebut diberikan pada masyarakat [22].

\subsection{Penggunaan Game}

Setelah melalui evaluasi game, maka game kemudian dipublikasi agar bisa digunakan oleh masyarakat.

\section{Hasil Penelitian}

\subsection{Hasil Implementasi Game}

Implementasi game memberikan penjelasan tentang skenario bermain yang terjadi dalam game selama dijalankan.

Pada saat pemain berada di menu utama, pemain memilih menu main untuk memulai memainkan game tersebut, seperti yang ditunjukkan pada gambar 7 .

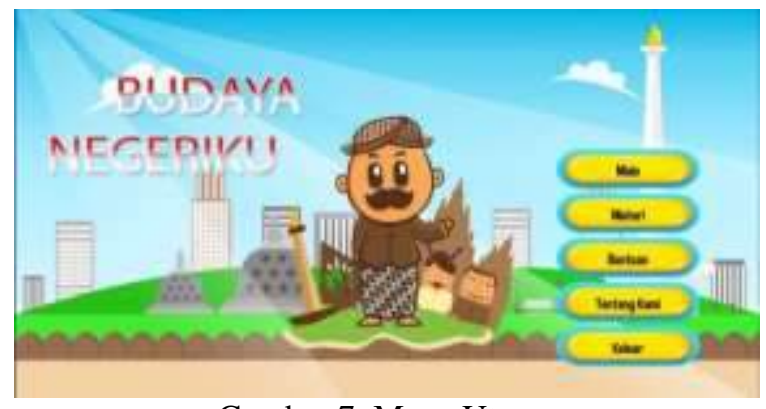

Gambar 7. Menu Utama

Setelah pemain memilih menu main, game akan menampilkan aturan main untuk level pertama sebelum game dimulai agar pemain tahu syarat-syarat yang harus dipenuhi untuk melanjutkan game ke level berikutnya. Jika pemain telah mengetahui aturan dan syarat yang harus dipenuhi, maka pemain harus menekan tombol lanjut untuk memulai game, seperti yang ditunjukkan pada gambar 8 .

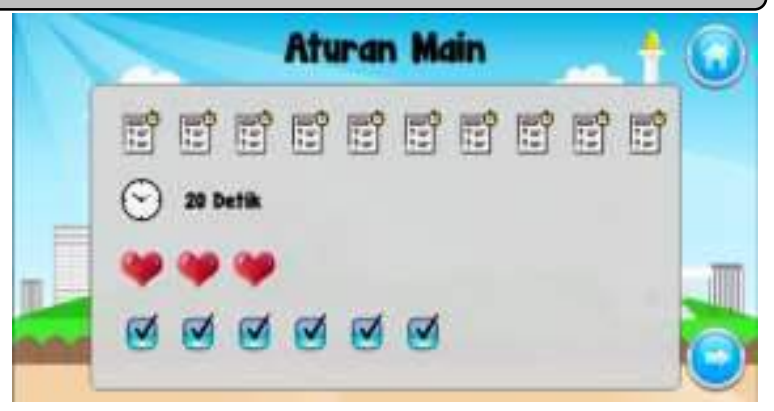

Gambar 8. Game Rule

Setelah menekan tombol lanjut, kemudian pemain sudah dapat memainkan game. Pemain harus bisa menyelesaikan 10 kuis yang telah diacak dengan batasan waktu yang telah ditentukan dalam aturan main, seperti yang ada pada gambar 9 bagian kiri.

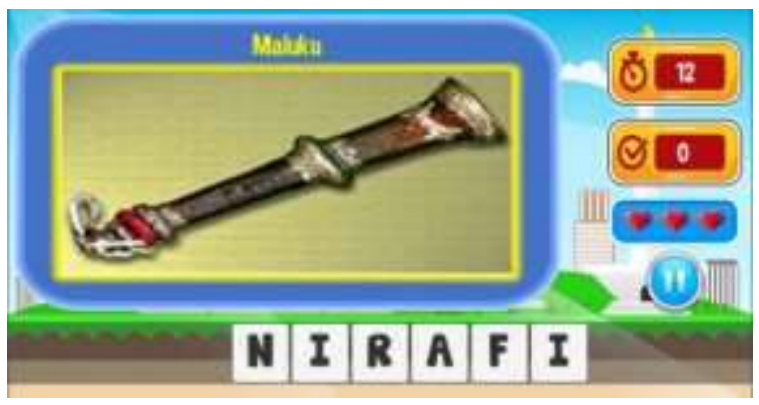

Gambar 9. Tampilan Gameplay

Jika pemain tidak dapat menyelesaikan kuis tersebut dengan benar hingga waktu yang tersedia habis maka nyawa pemain akan berkurang sebanyak 1 nyawa, seperti yang ada pada gambar 10 bagian kanan.

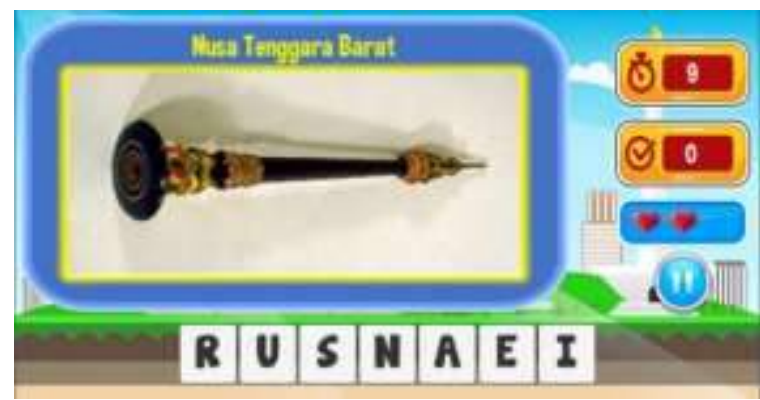

Gambar 10. Tampilan Nyawa Berkurang

Jika pemain kehabisan nyawa atau tidak dapat menjawab dengan benar sebanyak yang telah ditentukan, maka game akan langsung menampilkan keputusan dan hasil yang bisa kita lihat, seperti yang ada pada gambar 11 .

Namun jika pemain dapat menjawab kuis dengan benar sesuai dengan jumlah yang ditentukan oleh rule maka pemain berhak melanjutkan permainan ke level berikutnya, seperti yang ditunjukkan pada gambar 12 . 


\begin{tabular}{|c|c|c|c|c|c|}
\hline \multicolumn{3}{|l|}{ METIK VOLUME. 5 NOMOR. 22021} & ISSN-P 2442-9562 & \multicolumn{2}{|c|}{ ISSN-E 2580-1503 } \\
\hline $2 \times 1 / x=$ & 20 & 1 & 2 & 0 & Ulang \\
\hline s & 21 & 0 & 2 & 0 & Ulang \\
\hline & 22 & 8 & 1 & 2 & Lanjut \\
\hline & 23 & 7 & 1 & 2 & Lanjut \\
\hline & 24 & 6 & 1 & 2 & Lanjut \\
\hline Maaf Anda Tidak Memenuhi Aturan & 25 & 5 & 1 & 0 & Ulang \\
\hline Game Over & 26 & 4 & 1 & 0 & Ulang \\
\hline & 27 & 3 & 1 & 0 & Ulang \\
\hline Gambar 11. Hasil Gagal Lanjut & 28 & 2 & 1 & 0 & Ulang \\
\hline & 29 & 1 & 1 & 0 & Ulang \\
\hline & 30 & 0 & 1 & 0 & Ulang \\
\hline LEVEL COWWI & 31 & 7 & 0 & 1 & Lanjut \\
\hline & 32 & 6 & 0 & 1 & Lanjut \\
\hline & 33 & 5 & 0 & 0 & Ulang \\
\hline 900 & 34 & 4 & 0 & 0 & Ulang \\
\hline 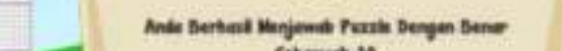 & 35 & 3 & 0 & 0 & Ulang \\
\hline 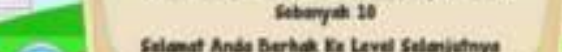 & 36 & 2 & 0 & 0 & Ulang \\
\hline 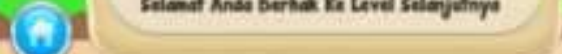 & 37 & 1 & 0 & 0 & Ulang \\
\hline Gambar $12 \mathrm{H}$ & 38 & 0 & 0 & 0 & Ulang \\
\hline
\end{tabular}

\subsection{Hasil Implementasi Forward Chaining}

Dalam penerapan metode forward chaining, penulis menggunakan variabel jawaban benar dan variable nyawa dalam memenuhi syarat untuk melanjutkan level berikutnya. Hasil dari penerapan metode forward chaining dituangkan ke dalam tabel berikut:

Tabel 4. Penerapan Metode Forward Chaing Dalam Menentukan Lanjut Tidaknya Pemain Ke Level Berikutnya

\begin{tabular}{ccccc}
\hline No & $\begin{array}{c}\text { Jumlah } \\
\text { Jawaban } \\
\text { Benar }\end{array}$ & $\begin{array}{c}\text { Jumlah } \\
\text { Nyawa }\end{array}$ & $\begin{array}{c}\text { Bintang } \\
\text { yang } \\
\text { Didapat }\end{array}$ & $\begin{array}{c}\text { Lanjut } \\
\text { /Ulang }\end{array}$ \\
\hline 1 & 10 & 3 & 3 & Lanjut \\
2 & 9 & 3 & 2 & Lanjut \\
3 & 8 & 3 & 2 & Lanjut \\
4 & 7 & 3 & 2 & Lanjut \\
5 & 6 & 3 & 2 & Lanjut \\
6 & 5 & 3 & 0 & Ulang \\
7 & 4 & 3 & 0 & Ulang \\
8 & 3 & 3 & 0 & Ulang \\
9 & 2 & 3 & 0 & Ulang \\
10 & 1 & 3 & 0 & Ulang \\
11 & 0 & 3 & 0 & Ulang \\
12 & 9 & 2 & 2 & Lanjut \\
13 & 8 & 2 & 2 & Lanjut \\
14 & 7 & 2 & 2 & Lanjut \\
15 & 6 & 2 & 2 & Lanjut \\
16 & 5 & 2 & 0 & Ulang \\
17 & 4 & 2 & 0 & Ulang \\
18 & 3 & 2 & 0 & Ulang \\
19 & 2 & 2 & 0 & Ulang \\
\hline & & & &
\end{tabular}

Dari hasil penerapan yang telah dijabarkan pada tabel 4 diatas, terdapat 38 kemungkinan yang terbagi menjadi 14 kemungkinan lanjut ke level berikutnya dan 24 kemungkinan untuk mengulang game yang didapatkan oleh pemain dalam memainkan 1 level game. Untuk lanjut ke level berikutnya pemain minimal harus bisa menjawab pertanyaan dengan benar sebanyak 6 pertanyaan dengan sisa jumlah nyawa tidak ada.

\subsection{Hasil Pengujian Perangkat}

Pengujian perangkat dilakukan secara langsung pada beberapa perangkat smartphone. Berikut ialah output dari pengujian yang sudah dilakukan pada beberapa smartphone:

Tabel 5. Pengujian Perangkat

\begin{tabular}{|c|c|c|c|c|}
\hline $\begin{array}{c}\text { Nama } \\
\text { Smartphone }\end{array}$ & $\begin{array}{c}\text { Versi } \\
\text { Android }\end{array}$ & $\begin{array}{c}\text { Resolusi } \\
\text { Layar }\end{array}$ & $\begin{array}{l}\text { Kesesuaian } \\
\text { Layar }\end{array}$ & Kelancaran \\
\hline $\begin{array}{l}\text { Redmi } \\
\text { Note } 5 \text { Pro }\end{array}$ & 9.0 & $\begin{array}{c}2160 x \\
1080 \\
(18: 9)\end{array}$ & Sesuai & Lancar \\
\hline $\begin{array}{l}\text { Zenfone } \\
\text { Max Pro } \\
\text { M2 }\end{array}$ & 9.0 & $\begin{array}{c}2880 x \\
1080 \\
(19: 9)\end{array}$ & $\begin{array}{l}\text { Tidak } \\
\text { Sesuai }\end{array}$ & Lancar \\
\hline $\begin{array}{l}\text { Asus } \\
\text { Zenfone } \\
\text { Live }\end{array}$ & 8.0 & $\begin{array}{c}1280 x \\
720 \\
(16: 9) \\
\end{array}$ & Sesuai & Lancar \\
\hline $\begin{array}{l}\text { Asus Rog } \\
\text { Phone II }\end{array}$ & 9.0 & $\begin{array}{c}2340 x \\
1080 \\
(19.5: 9)\end{array}$ & $\begin{array}{l}\text { Tidak } \\
\text { Sesuai }\end{array}$ & Lancar \\
\hline
\end{tabular}

Hasil pengujian menunjukkan bahwa game yang dikembangkan di semua perangkat mudah digunakan, berdasarkan 
beberapa pengujian yang dilakukan pada beberapa smartphone Android dan resolusi layar. Namun, beberapa perangkat ponsel pintar dengan rasio aspek di atas 18,9 tidak kompatibel dengan tampilan game di perangkat untuk kompatibilitas layar, seperti pada gambar dibawah ini :

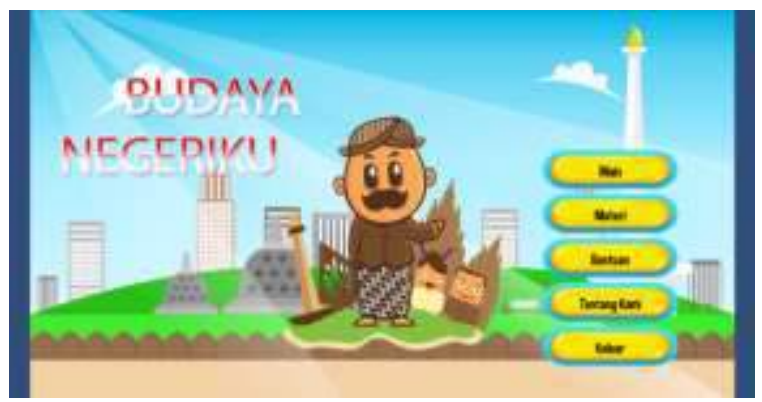

Gambar 13. Ketidaksesuaian Tampilan Aplikasi

\subsection{Hasil Pengujian Kuesioner}

Pengujian kuesioner dilakukan secara online maupun secara langsung diberikan ke beberapa pelajaran untuk memberikan penilaian terhadap aplikasi yang telah dibuat dengan. Berikut hasil yang didapatkan:

- Jumlah responden yang mengisi kuesioner sebanyak 53 orang, dengan status responden terbanyak adalah pelajar/siswa-siswi dengan kisaran usia 11-20 tahun.

- Sebanyak 78,1\% responden cukup mengetahui apa saja warisan budaya Indonesia.

- Sebanyak $82,3 \%$ responden sangat mudah mencari informasi mengenai warisan budaya Indonesia.

- Sebanyak 94,3\% responden menyatakan sangat setuju warisan budaya Indonesia itu penting bagi masyarakat.

- Sebanyak 95,5\% responden menyatakan sangat setuju bahwa warisan budaya Indonesia itu perlu dijaga dan dilestarikan.

- Sebanyak 91,7\% responden menyatakan sangat setuju apabila ada aplikasi yang mampu memberikan informasi tentang warisan budaya Indonesia.

- Sebanyak 81,5\% responden mengemukakan bahwa game ini mudah dioperasikan.

- Sebanyak $82,3 \%$ responden sangat setuju bahwa game ini menarik untuk bisa dimainkan.
- Sebanyak $80,4 \%$ responden menyatakan peraturan-peraturan game ini sudah jelas.

- Sebanyak $83 \%$ responden menyatakan sangat setuju informasi yang ditampilkan mudah dipahami.

- Sebanyak 84,2\% responden menyatakan sangat setuju bahwa tombol-tombol pada game mudah dioperasikan.

- Sebanyak $84,9 \%$ responden menyatakan sangat setuju bahwa tombol-tombol pada game ini berfungsi dengan seharusnya.

- Sebanyak $81,5 \%$ responden menyatakan sangat setuju dengan ukuran gambar yang ditampilkan.

- Sebanyak $84,2 \%$ responden menyatakan sangat setuju bahwa lagu yang disajikan sudah jelas untuk didengar.

- Sebanyak 84,5\% responden menyatakan sangat setuju jika objek warisan budaya yang ada ditampilkan sudah jelas.

- Sebanyak $81,9 \%$ responden menyatakan sangat setuju jika tampilan yang ada pada game ini menarik.

- Sebanyak 90,6\% responden menyatakan sangat setuju jika game ini dirasa sangat berguna saat dimainkan.

- Sebanyak 90,6\% responden menyatakan sangat setuju jika dengan adanya game ini dirasa bisa membantu pengguna mengetahui lebih banyak warisan budaya Indonesia.

- Sebanyak 87,2\% responden mengemukakan sangat setuju jika game ini bisa sangat bermanfaat bagi penggunanya.

- Sebanyak 83,8\% responden mengemukakan pendapat yaitu sangat setuju jika game ini sangat memuaskan.

- Sebanyak 89,8\% responden mengemukakan pendapat yaitu sangat setuju jika game ini cocok diberikan kepada khalayak umum.

\section{Kesimpulan}

Berdasarkan hasil dan pembahasan sebelumnya, dapat ditarik kesimpulan sebagai berikut berdasarkan tujuan penelitian yang ingin dicapai:

- Penerapan metode forward chaining dalam pengembangan game edukasi warisan budaya Indonesia sangat berperan besar dikarenakan pemain yang 
telah mencoba game yang di bangun ini merasa menarik untuk dimainkan.

- Game yang telah dikembangkan ini memperkenalkan warisan budaya Indonesia seperti alat musik tradisional, senjata tradisional, rumah adat, tari adat, serta lagu daerah menggunakan berbagai jenis game seperti susun kata, puzzle, kuis dan tebak lagu. Selain itu game ini juga memberikan fitur materi yang menjelaskan secara detail warisan budaya Indonesia berdasarkan provinsinya masing-masing sehingga pemain bisa lebih mengenal warisan budaya Indonesia tersebut.

\section{Saran}

Berdasarkan hasil evaluasi pada game warisan budaya Indonesia, terdapat beberapa saran untuk pengembangan game ini selanjutnya sebagai berikut:

- Perlu ditambahkan sistem skor tertinggi (Highscore), sehingga memberikan tantangan kepada pemain untuk mencetak skor tertinggi.

- Diharapkan game ini dapat ditambahkan video pada detail tari sehingga informasi yang diberikan lebih jelas dan mudah dipahami.

- Untuk pengembangan game ini selanjutnya, diharapkan game ini kesesuaian layarnya bisa support untuk segala jenis layar smartphone.

- Game ini masih dapat disempurnakan lagi. Oleh sebab itu, perlu dilakukan pengembangan game yang lebih baik dari segi desain maupun materi untuk meningkatkan manfaat game ini di masa depan

\section{Daftar Pustaka}

[1] M. B. Firdaus, D. S. Habibie, and F. Suandi, "Perancangan Game OTW SARJANA Menggunakan Metode Forward Chaining," vol. 6, no. 2, pp. 6674, 2021.

[2] N. Dengen, H. S. Pakpahan, G. F. Putra, M. B. Firdaus, R. Wardhana, and A. Tejawati, "An Augmented Reality Model Physical Transformation Learning," ICEEIE 2019 - Int. Conf. Electr. Electron. Inf. Eng. Emerg. Innov. Technol. Sustain.
Futur., pp. 255-259, 2019, doi: 10.1109/ICEEIE47180.2019.8981444.

[3] M. B. Firdaus, J. A. Widians, and R. Rivaldi, "Augmented Reality Marker Based Tracking Kayu Bahan Baku Kerajinan Khas Kalimantan Timur," $J$. Ilm. Ilmu Komput., vol. 16, no. 1, pp. 1-6, 2021.

[4] W. H. S. Dos Santos, R. M. G. Silva, R. C. M. Santos, and M. F. Moreno, "A knowledge oriented virtual reality tool for exploring seismic data," Proc. - 2018 IEEE Int. Conf. Artif. Intell. Virtual Reality, AIVR 2018, pp. 195-196, 2019, doi: 10.1109/AIVR.2018.00045.

[5] M. B. Firdaus, E. Budiman, Haviluddin, M. Wati, H. J. Setyadi, and H. S. Pakpahan, "An openness of government website content using text analysis method," Int. J. Eng. Adv. Technol., vol. 8, no. 5, pp. 1461-1466, 2019, doi: 10.35940/ijeat.E1214.0585C19.

[6] U. Hairah, A. Tejawati, E. Budiman, and F. Agus, "Borneo biodiversity: Exploring endemic tree species and wood characteristics," Proceeding - 2017 3rd Int. Conf. Sci. Inf. Technol. Theory Appl. IT Educ. Ind. Soc. Big Data Era, ICSITech 2017, vol. 2018-Janua, pp. 435-440, 2018, doi: 10.1109/ICSITech.2017.8257152.

[7] M. B. Firdaus, I. M. Patulak, A. Tejawati, A. Bryantama, G. M. Putra, and H. S. Pakpahan, "Agile-scrum Software Development Monitoring System," ICEEIE 2019 - Int. Conf. Electr. Electron. Inf. Eng. Emerg. Innov. Technol. Sustain. Futur., pp. 288-293, 2019, doi: 10.1109/ICEEIE47180.2019.8981471.

[8] M. Mustika, E. P. A. Sugara, and M. Pratiwi, "Pengembangan Media Pembelajaran Interaktif dengan Menggunakan Metode Multimedia Development Life Cycle," J. Online Inform., vol. 2, no. 2, p. 121, 2018, doi: 10.15575/join.v2i2.139.

[9] M. B. Firdaus, J. A. Widians, and J. Y. Padant, "Augmented reality for interactive promotion media at Faculty of Computer Science and Information Technology Mulawarman University," J. Phys. Conf. Ser., vol. 1341, no. 4, 2019, doi: 10.1088/1742-6596/1341/4/042017.

[10] M. B. Firdaus, Z. Arifin, and R. W. Priatna, "Testing the Augmented Reality Functional Suitability of Wood as Raw Materials for Typical Crafts of East Borneo," vol. 04, no. 03, pp. 109-115, 
2021.

[11] A. Tejawati, M. B. Saputra, M. B. Firdaus, S. Fadli, F. Suandi, and M. K. Anam, "Media Promosi Penangkaran Rusa Sambar (Rusa Unicolor) Sebagai Ekowisata Di Penajam Paser Utara Berbasis Virtual Reality," J. Inform. dan Rekayasa Elektron., vol. 2, no. 2, p. 52, 2019, doi: 10.36595/jire.v2i2.118.

[12] A. Tejawati, M. B. Firdaus, M. N. Ihwan, F. Alameka, and M. K. Anam, "Prototipe Media Pembelajaran Rambu Lalu Lintas Berbasis Android," Metik J., vol. 5, no. 1, pp. 2021, 12-18, doi: 10.47002/metik.v5i1.210.

[13] A. Tejawati, H. Aulia, M. B. Firdaus, F. Suandi, L. Lathifah, and M. K. Anam, "Pemanfaatan Video Dan Animasi Dengan Karakter Hela Pada Pandangan Umum Terhadap Anak Pengidap Autistik," J. Inform. dan Rekayasa Elektron., vol. 2, no. 2, p. 62, 2019, doi: 10.36595/jire.v2i2.120.

[14] L. Lathifah, S. Suaidah, M. B. F, M. K. Anam, and F. Suandi, "Pemodelan Enterprise Architecture Menggunakan Togaf Pada Universitas X Palembang," J. Teknoinfo, vol. 15, no. 1, p. 7, 2021, doi: 10.33365/jti.v15i1.865.

[15] M. B. Firdaus, N. Puspitasari, E. Budiman, J. A. Widians, and N. Bayti, "Analysis of the effect of quality mulawarman university language center websites on user satisfaction using the webqual 4.0 method," Proc. ICAITI 2019 - 2nd Int. Conf. Appl. Inf. Technol. Innov. Explor. Futur. Technol. Appl. Inf. Technol. Innov., pp. 126-132, 2019, doi: 10.1109/ICAITI48442.2019.8982143.

[16] Q. Qumillaila, B. H. Susanti, and Z. Zulfiani, "Pengembangan Augmented Reality Versi Android Sebagai Media
Pembelajaran Sistem Ekskresi Manusia," J. Cakrawala Pendidik., vol. 36, no. 1, pp. 57-69, 2017, doi: 10.21831/cp.v36i1.9786.

[17] J. M. Patricio, M. C. Costa, and A. Manso, "A Gamified Mobile Augmented Reality System for the Teaching of Astronomical Concepts," no. June, pp. 1-5, 2019, doi: 10.23919/cisti.2019.8760658.

[18] Bagas Kurniawan, Ade Ajie Ferizal, and Iskandar, "Rancang Bangun Game Badex Hurdle Berbasis Multimedia Menggunakan Macromedia Flash 8," TEKNOSAINS J. Sains, Teknol. dan Inform., vol. 8, no. 1, pp. 1-9, 2021, doi: 10.37373/tekno.v8i1.71.

[19] M. B. Firdaus, E. Budiman, M. F. Anshori, J. Teknologi, and U. Mulawarman, "Evaluasi Skema Panduan Game Berbasis Motion Graphic Animation Pada Esports Bergenre Multiplayer Online Battle Arena," JURTI Univ. Mulawarman, vol. 4, no. 1, p. 36, 2020.

[20] A. Tejawati, E. K. Pradana, M. B. Firdaus, F. Suandi, L. Lathifah, and M. K. Anam, "Pengembangan Video Dokumenter 'Wanita Dan Informatika' Di Lingkungan Fkti Universitas Mulawarman," J. Inform. dan Rekayasa Elektron., vol. 2, no. 2, p. 72, 2019, doi: 10.36595/jire.v2i2.121.

[21] M. B. Firdaus, A. Tejawati, E. Budiman, M. R. Wahyudianto, and M. K. Anam, "Virtual Reality Museum Mulawarman Berbasis Video 360," SAINTEKOM, vol. 1770, pp. 130-141, 2021.

[22] M. M. Raditya, F. Fauziah, and R. T. Komalasari, "Rancang Bangun Game IQ Test Preparation dengan Mengimplementasikan Metode FSM," $J$. Sist. dan Teknol. Inf., vol. 8, no. 1, p. 128, 2020, doi: 10.26418/justin.v8i1.37941. 